\title{
Business Models and the Diffusion of Eco-innovations in the eco- mobility sector
}

\author{
Isabelle Nicolai \\ U. Paris Saclay (UVSQ), Guyancourt, France, and \\ Sylvie Faucheux \\ LIRSA, CNAM, Paris, France
}

The transportation of goods and people represents roughly $30 \%$ of overall energy expenditures and, is the source of nearly one quarter of world greenhouse gas emissions. A big part of the responsibility in this, belongs with road transport, with $80 \%$ of the energy consumed in the transport sector. And, within this, private vehicle use represents $60 \%$ of the greenhouse gas (GHG) emissions coming from road transport.

The road transport sector is thus at the root of a wide range of environmental and health externalities - GHG emissions, local pollution, noise, accidents and road safety risks, congestion (with associated stress and time costs) and, the sealing of productive land for roads and associated infrastructures. This leads to reflection within and around the automobile industry, on the conception and commercialisation of new products that will reduce these negative externalities - including, among others, the ambitious targets of GHG emissions for 2050 : a reduction of $60 \%$ in GHG emissions for the transport sector compared with 1990 (European Commission 2011).

There are several other mutations in road vehicle markets that will equally impact on the innovation strategy of actors in the « car » ecosystem. These include :

- Increasing urbanisation that will tend to accentuate negative impacts of car use. The social costs of congestion, for example, are estimated to rise by $50 \%$ between now and 2050 , with a monetary value of several billion euros per year, if nothing is done to slow the flux of car traffic. What mobility solutions might be proposed, to respond to individual mobility needs while nonetheless proposing products or mobility services with as low a social cost as possible?

- Increases in average incomes in the most populous countries of the world (China, India, Indonesia, regions of Africa) will lead to greatly increased demand for cars and car use. This increasing access to individual mobility will come at what environmental cost?

- Several major changes in mobility behaviour patterns and «lifestyles» can be anticipated for coming years, linked on the one hand to habits and expectations of the new « connected » generations and, on the other hand to the growing « senior » (elderly) populations. One might imagine a changing demande for safer and more «connected» 
(smart) mobility options, more easily accessible and adapted to different needs, and more environmentally friendly. What might be the strategies on the supply side?

- At the technological level, various «lock-in » factors need to be taken into account. For example, continuing improvements in the environmental performance of combustion motors, may push back the date at which electric-powered mobility becomes fully competitive. A dramatic lowering of vehicle $\mathrm{CO}_{2}$ emissions will be possible only if there are radical changes also in production and consumption systems, in patterns of good transportation, expectations of comfort and so on... How will the innovation waves coming from different sectors be linked or melded? The penetration of ICT or "smart" technologies into all aspects of mobility, including "smart car" technologies contributing to better per unit performance on some environmental criteria, is another example of emerging system complexities to be resolved.

- And to complete the list, allowance must be made for the very high levels of "inertia" characteristic of many cycles of innovation and of the maturation of new vehicle technologies and mobility infrastructures, for which the expected returns on investment are quite far away in time.

The Aramisauto/TNS Sofres opinion study carried out in May 2013, has highlighted the way that the changes in mobility solutions across social, economic and environmental lines, are contributing in a cumulative way to radically altered perceptions of the motor vehicle for individual mobility. In this paper, we seek to identify and to characterise the current evolution of «sustainable mobility» solutions. First of all (Section $§ 1$ ) we consider this trend as an expression of eco-innovation and, seek to characterise the patterns of innovation uptake and diffusion. Then, in Section $\S 2$, we look at the impacts of the emerging business models for the introduction of these eco-innovations, on the wider "eco-system" of mobility. In particular, the mix of actors, job profiles and sectors implicated in the mobility domain is changing quite radically, across all aspects including risk and insurance, energy systems, service providers, socalled "smart" systems and associated data management, and public-private partnership forms. 


\section{§1. Eco-mobility and New Business Models}

We define eco-mobility as the set of "sustainable mobility" solutions, ${ }^{1}$ which encompasses all mobility options - individual or collective, public or private - that contribute positively to economic and environmental performance challenges of sustainability (including notably, but not exclusively, energy efficiency and reductions in GHG emissions; cf. Pillot 2011). Eco-mobility is thus a field or class of eco-innovation as defined by Klemmer et al. (1999). ${ }^{2}$

In view of these features, eco-mobility seems necessarily to engage paradigm shifts (at the levels both of end-use and of technologies) and to require new frameworks for the interpretation and analysis of strategies and relations of actors in the sector. For example, the growing success of different forms of car-sharing may well be a sign of a progressive shift (voluntary and/or imposed by economic and environmental realities) from an economy of individual ownership towards an economy of services, that is, based more on use than on possession.

By "paradigm shift" we refer, therefore, as much to changes in attitudes and patterns of use, as to innovations in the technologies themselves. In this, we align with the definition provided by Mackay \& Metcalfe (2002) for whom, a disruptive innovation impacts simultaneously on the structure of supply and the patterns of goods/service demand. This is our starting point for our analysis of eco-mobility as eco-innovation and our investigation of the factors contributing to value creation and to the business models that emerge.

\subsection{Eco-mobility as "Disruptive" Eco-innovation}

A review of the different strands of literature in economics of innovation (including institutional, ecological, evolutionary and neoclassical traditions - see among others: Rennings 2000, Hellström 2007, Carrillo-Hermosilla et al. 2009, Nill et Kemp 2009) highlights three factors as determinant for characterising eco-innovation :

i) A problem of double externality - positive externalities of network development and $R \& D$; and negative environmental externalities ;

ii) A necessary engagement of regulatory apparatus to governe the innovation process ;

iii) And, more widely, the importance of social and institutional dimensions defining acceptance and uptake of the innovation.

$1 \quad$ This definition includes a great variety of initiatives across wide fields of application : car-sharing, developments of the service economy, electric vehicles, «smart cars » and «connected » vehicle fleets, automatic vehicles, « smart» multimodal systems, smart parking....

2 Eco-innovation is here defined as a process of development of new forms of organisation, new services, products or technological processes that contribute to the reduction of negative environmental externalities and/or to the achievement of environmental sustainability objectives. 
The justifications most frequently cited for eco-innovation at the firm level, have both social and environmental dimensions (cf., Orsato 2006; Azzone et Noci 1998 ; Porter et Kramer 2011). The challenge is to integrate or "internalise» new environmental (and social) performance constraints within the firm's innovation strategy: that is, to respect (and indeed, to anticipate) the new performance requirements as a 'plus' in terms of legitimacy (mentioned already by Di Maggio et Powell 1983) or as a positioning tactic for the construction of a competitive differentiation (Dal Bo 2006).

The eco-mobility domain follows this pattern. New needs appear, and user behaviour changes in a complex coevolution with regulatory frameworks. At the level of the global automobile industry, the supply side is characterised by several different pressures: the top rank constructors (notably German and Japanese) have a significant influence on the mature automobile markets; whereas new entrants (notably East and South Asian) have a driving role in many emerging and rapidly growing markets. New needs or performance requirements are expressed in terms of "low carbon" mobility and "digitalisation" or "smart" technologies. Vehicle users are increasingly aware of the costs associated with their movements including the negative externalities associated with private vehicle use. So the demand for vehicles and mobility services is also changing, opening up new market opportunities but also new risks for innovators in the industry. At the political level, governance agencies are caught between the public demand for ever more mobility (faster, easier, more comfortable, cheaper) and, the public pressure also to respond to environmental and health quality challenges. This can lead to regulatory interventions seeking to "find a balance" across the spectrum of performance considerations and change factors. But there is often uncertainty as to the real capacity of political decision-makers to promote appropriate infrastructure investments (e.g., imposing rules about electric car recharging facilities) and administrative frameworks (e.g., need for the introduction of autonomous cars).

In order to characterise the dynamics of eco-mobility innovations, we will exploit the typology of eco-innovation proposed by Faucheux \& Nicolaï (2011). This is a multi-dimensional typology, which puts a strong emphasis on the demand side and the "social dimension" of "users and "use" patterns. We apply this to eco-mobility, the following considerations: 
- The field of application of the eco-innovation (cf. Schumpeter 1934). For eco-mobility, we are as much interested in organisational change (market structure, value chain, purchase and use patterns) as in the technology innovations themselves. ${ }^{3}$

- Innovation intensity, referring to the degree of novelty associated with the new mobility forms. Innovations are classified in terms of "incremental" or "radical" change (Freeman \& Soete 1987). Incremental innovations are improvements to products or production techniques, bringing better quality, productivity and diversity (etc.). Such innovations is present everywhere in the history of technology. For example, the new Michelin product "Tall and Narrow" is an incremental innovation aimed at better energy efficiency of the vehicle. By contrast, the electric car is a more "radical" innovation.

- The scope of the innovation. This relates to the way that production processes are changed (e.g., add-on or integrated technology change, in the terminology of Frosh 1995). Add-on technologies are adjustments to existing processes or products, seeking for example to modify emissions or solid wastes composition so as to reduce environmental damage associated with production or consumption.

- The nature of the new know-how. As a function of the intensity and the scope of the innovation, very different knowledge needs and new skill requirements can emerge which can have a very strong significance for innovation dynamics in terms of both formal and tacit knowledge (Nonaka \& Takeuchi 1997). In the field of eco-mobility, many of the new knowledge are transversal (or cross-cutting) relative to established skill-sets and trades. Thus, for example, the design and manufacture of a "smart car" or connected vehicle requires close collaboration between the car-makers and partners from data management and ICT service sectors. This implies the need to develop organisations' coordination capacities as well as their ability to integrate mixed inputs into a group system through mindful contributions and representations (Weick \& Roberts 1993). An illustration is the partnership between Technicolour (ex Thomson) and Peugeot to develop a smart vehicle that maries digital information technologies with traditional vehicle concepts for electronic driver assistance, passenger comfort and entertainment. The Citroën C4 Picasso will be the first PSA vehicle to incorporate Qeo, providing for a better interaction between the car technology and the smartphones/tablettes of the car users and, by extension, with electronic devices left at home or at work.

3 This includes notably the « economy of services » (cf., Fan et al. 2006). The replacement of the sale and purchase of material goods by the provision of a mobility "service ", is often correlated with a reduction in the energy and materials intensity of the mobility service - with potential environmental as well as commercial gains. 
- The innovation support, or principal carrier/driver of the innovation. In some cases, eco-innovation may be impelled by regulation (in turn pushed by social pressures, cf., Barabel et alii 2010 on the theme of business ethics) ; in other cases the motive of competitive positioning may dominate (Azzone \& Noci 1998). The factor of "sustainability" can here be presented as a source of added value (Porter \& Kramer 2011). Eco-mobility innovations that encourage "environmentally friendly" behaviour (that is, less intensive in natural resource use, virtuous in terms of pollution abatement, etc.) with mobility services that remain profitable, are thus a "win-win" ideal in the innovation strategies of the automobile industry.

- Acceptability to users. For success with eco-innovations, businesses need, ideally, to be able to count on the acceptance of innovations "in the market" and, the absence of societal controversy. Factors influencing acceptability and acceptance can be identified on the supply side (technology of production and diffusion) and also directly in terms of of users' behaviour (Pujari 2006; Dantan et alii 2015). The question of acceptability can be explored, in theoretical and empirical terms, as a problem of a "social contract" - that is, reaching collective agreements (both formal and tacit) around the new modalities of production and dissemination of goods and services.

In sum, eco-mobility innovation strategies addressing the "double externality" challenge mentioned earlier, must bring together technology push, market pull and regulatory push (Rennings 2000). These features in combination, lead typically to eco-mobility solutions as having a "disruptive" character relative to the status quo of the transport sector. More or less radical changes are implied both in technology systems and knowhow, and in user patterns. A feature of eco-mobility innovation is (as Astley and Fombrun 1983 would suggest), the need for regulatory mechanisms that facilitate the development of new network structures that permit individuals' actions and decisions to evolve along with the infrastructures of production and service provision. There is a complex dynamic of "push" and "pull" across different stakeholder groups, whose economic interests and opportunities are mediated by regulatory processes (Di Maggio \& Powell 1983; Greenwood et alii 2002). Thus, the governance process itself is likely to evolve, with the emergence of new lobbies and pressure groups, and changes in patterns of influence.

Following the arguments of Porter et Kramer (2011), businesses and other stakeholders within the eco-mobility eco-system have an interest to engage voluntarily in concerted action, so as to influence the way that the regulatory environment changes and to ensure a coherence of new 
infrastructures relative to changing supply and demand patterns. ${ }^{4}$ Recognising this need for proactive partnership building under conditions that are permanently evolving, becomes one of the key arguments for the so-called Open Innovation model (Chesbrough 2003, 2006). The ecomobility sector, characterised by the emergence of a new economy of services and by new partnership arrangements at all levels (described by Teece 2007 as a permanent process of "dynamic capability" building5), is a clear example de facto of open innovation (cf. also, TorrèsBlay 2000).

\subsection{Eco-mobility - from disruptive innovation to new business models}

Eco-mobility is a major scientific and industrial challenge precisely because, for a key sector of the economy, there is a need to respond in new ways to users' mobility needs and to have them "come on board" (so-called "demand-pull" innovation, but where the social demand is itself evolving) at the same time as new business models are being explored to structure the changing technological and geographical conditions (so-called "technology push") on the "supply side". All of this in an institutional environment that, as we have described, is itself uncertain.

Eco-mobility is thus a major case of "disruptive innovation", in the sense used by Mackay \& Metcalfe 2002) and by Christensen (2006), in which the innovation process induces major structural changes to supply and to demand conditions. The new technological possibilities permit and impose novelty in the sense of new production and use situations that are completely unfamiliar to most of the people involved, and in the sense of provoking significant (sometimes wholesale) changes in governance and infrastructures. This is disruptive in the sense that "nothing is as it was before", neither in terms of production and supply structures nor in terms of consumer behaviour. ${ }^{6}$

The concept of disruptive innovation is thus closely aligned to that of "creative destruction" developed in different ways by evolutionary economists (Nelson \& Winter 1982; Schumpeter 1934, Passet 2010). In this vision, what counts is not the 'new technology' in itself, but the way that it is mobilised in business and societal strategies (targeting different perceived needs, goals and opportunities), becoming a vector in a "cumulative causation" — that is, a co-evolution of

4 Porter \& Kramer (2011) signal, in this regard, three main axes for the creation of « shared value » - the creation of new products or services ; reorganisation of the value chain ; creation of a local cluster of competencies. Each of these axes can produce joint »winners » (but of course there can also be losers, those whose partnership concepts did not get « picked up » by the emergent choices of the ecosystem).

5 Dynamic capabilities are here defined as a business's capacity to integrate, build and reorganise internal and external competencies in order to better deal with changing environments.

$6 \quad$ The transitions since the 19th century (and in many parts of the world, during the 20th century) from river and canalbased transportation,and from the horse and cart, to trains and motorised individual transport, are a clear demonstration of how radical these transformations can be. 
technology, business models and practices, governance structures, consumer behaviour, social relations and societal values (cf. Norgaard 1994).

As regards eco-mobility, it is easy to identify several features of discontinuity or "rupture", expressed partly in the emergence of new commercial partnership structures and business models, and partly in terms of wider infrastructure, governance and societal changes. In particular we can observe:

1 The emergence of new technological waves, such as electro-mobility (where existing automobile technologies and new ICT technologies become interwoven), which is initially under-performing (in terms of cost and consumer expectations) relative to the 'traditional' products but, which is progressing much more rapidly than the more established automobile conventions.

2 The new technology is introduced by "fringe" actors in the market, sometimes even outside established markets. (As remarked by Christensen (1997), one of the dilemmas confronting an innovator is that radical innovations are rarely introduced by the dominant business groups, or at least not until they consider it necessary or possible to keep their share in a changing market...). For example, in the experiments in car-sharing in France, one of the key actors in Bolloré which historically is not present in the automobile sector. To the extent that this innovation is taken up, it constitutes a shift away from production and ownership models that have been stable for many decades, and towards new business models for use and supply of mobility solutions.

3 The introduction of the "new technology" thus imposes a learning curve on the mobility suppliers, in that they must explore, anticipate and "internalise" the new or emerging patterns of consumer behaviour in order to represent effectively (or "sell") the opportunity of mobility services in the changing markets. Those on the 'technical' side of production cannot rest isolated from the wider changes in behaviour and user attitudes. For the new markets to "emerge" and grow, there must be created a virtuous circle between "demand pull" (mobility needs and forms) and "technology push" (the products supplied). Sometimes 'new' actors are more easily able to engage on this sort of learning path, not being cognitively saturated by the concepts and habits of the already existing markets.

We can envisage, as for any "disruptive innovation", a 'sigma' pathway of penetration where, each phase of technology development and uptake is associated with a specific profile of users. The latter, as users/consumers of the services and products in question, are thus classified according to the phase in time of their engagement with the new technology. In summary, the early-adopters of the «smart car» are typically visionary spirits inspired by the idea of the new 
technology and its possibilities; the early-majority (which marks the passage from a «niche economy » to a mass-market) is more pragmatic in the sense of giving weight to the classical factors of rational choice (price, reliability, range of choice, convenience and interoperability...).

A business strategy for managing the marketing of the innovations in products and services, must develop partnerships and business models adapted to each phase and to each category of consumers who respond to very different stimuli. Successful management of the transitions from one phase to the next (early adopters, to early-majority, to mass market...) is the sine qua non of the innovation wave itself. To the extent that a class of « radical » innovation becomes adopted at a large scale, the cumulative causation of demand-pull and technology-push is associated, in the end, with radically changed structures of market activity, economic governance and lifestyle.

Following Demil \& Lecocq (2010), we can consider the business model as, in a general sense, the way that a business chooses to organise the process of generating its income. In effect, the business model is the "architecture of value" (Moingeon \& Lehmann-Ortega 2006), the set of procedures and principles permitting a business and its partners to create value, bringing together the capacity to offer goods and services with the willingness of clients to buy. This necessarily encompasses, except in the simplest cases, various intermediate steps and exchange relations of the "value chain", from raw materials to after-sales service and recycling. In this regard, analysis of the business models associated with an innovation process is, across the different concepts, models and paradigms, nothing less than analysis of the social dynamics of innovation itself (Amit \& Zott 2001). The business model for a radical innovation is a tool of creative destruction, it is integrative in new ways of the factors and partners in value creation.

This approach permits us to analyse the business model or models of each partner in an innovation ecosystem - in a systems perspective (Osterwalder \& Pigneur 2011) taking account the technological, commercial, cognitive and political interdependencies with other partners. ${ }^{7}$

In particular, the business model must incorporate - explicitly or tacitly - a vision of consumer behaviour and of key factors bearing on their interest in and adoption of the new products or services. (Ganguly et alii, 2011). This is not a static process of market intelligence. Rather, innovative enterprises must, as a condition of success, to some extent influence, mould and give substance to "social demand" (Davis 1989) - that is, influence during the pioneering "demonstration" phase, the ways that future supply and demand are formed within the society

$7 \quad$ For an application to the case of the electric vehicle, see the work of Pillot (2013) in the context of the VeDeCom Institute in France. 
at large. For example, as argued by van der Vooren et Alkemade (2012)in their recent study on the electric car,

"the impact of consumer selection pressure on the future success of different low emission vehicle technologies can be substantial. In the model, consumer adoption decisions codetermine the direction of technological change»

This view of the business models highlights the coevolution of supply and demand, and suggests the importance of giving attention in business strategy to the identification and understanding of "early adopters". These are the people that, one way and another, informs the early phases of conception, provides feedback and thus ex post evaluation of the first phases of supply and, acts as a lever of market growth moving from demonstration to the "early majority" category of users.

The role of "early adopters" in making or breaking a market strategy for an innovation can be decisive. Nonetheless, the "demand" for innovation is not an exogenous variable and, it is up to the innovative enterprise or partnership to identify factors that may facilitate or inhibit uptake.

Eco-mobility being very much a domain of networks and social relations, it becomes particularly interesting in this regard to consider the so-called "Neighbour Effect", meaning the increasing attractiveness of "joining in" a network activity as the level of visible activity (use and users) increases. This Neighbour effect has recently been the object of an econometric analysis in Canada, in a study of consumer vehicle purchase preferences, notably for hybrid and electric vehicles (Mau et alii, 2008). In as much as attractiveness is enhanced by such factors as the Neighbour Effect (e.g., seeing others using the new technology may be reassuring as to its performance, or a proof of social acceptability, or even a matter of prestige (snobbery, "Keeping up with the Jones, etc.), the marketing strategy can seek to highlight and amplify such effects. Here as in other respects, it is a matter of identifying and responding to the different motivations of consumers, of "investing in" and reinforcing these motivations -- whether related to environmental performance, social positioning, love of novelty, political payback or whatever.

\section{§2. System effects of eco-mobility innovations}

In sum, eco-mobility is field of "disruptive" innovation, in several ways. It entails the development of new partnerships on the technology and production side; it responds to a new configuration of social demands for environmental performance, comfort and flexibility for users of different ages; it is characterised by experiments with new marketing strategies and economic models in the vision of an "economy of services" and with a high consciousness of network integration and "positional" factors in the offer and uptake of new mobility solutions; 
and it both responds to and requires innovation in the regulatory environment. In all these ways, eco-mobility innovation is tending to provoke substantial change to the existing "ecosystem" of transport and mobility markets and this is the feature to which we turn now.

Consider first, the sorts of changes taking place on the supply side. As already mentioned, ecomobility is characterised by a pronounced shift in the mix of partners in the value chain with, on the one hand the integration of 'new' actors notably from the electrical, electronics and information technology sectors; and, on the other hand, the modification of the roles (and in some cases the disappearance altogether) of traditional partners (for example, the distributors of refined petroleum products have a much reduced place in the production and servicing of electric cars...). Pillot (2011) has formulated the key features this ongoing process of industrial restructuring process, as shown below.

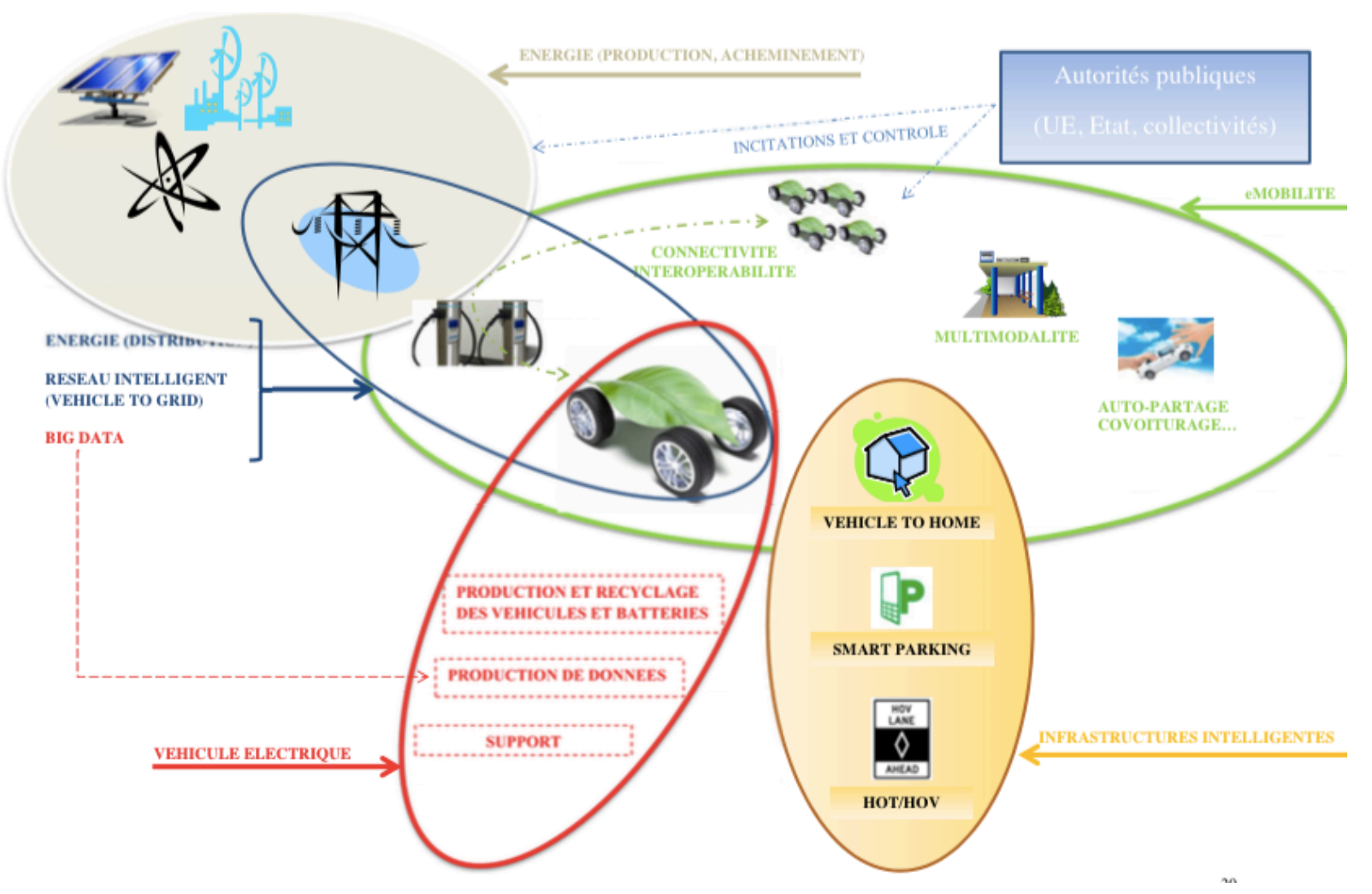

This restructuring of the mobility "eco-system" is complex, and is a source of both uncertainties and stress. The emerging ecosystem of eco-mobility is composed of many different sub-systems, each responding to different needs along the value chain, relative to different services and products and to the signals coming from consumers (visibility, price acceptability, perceived quality...) in the emerging markets. Not only is the speed of restructuring very different from sub-system to subsystem but, also the mix of 'new' and 'traditional' actors can be very different. New and old partners thus may have very different interests in the growth of eco-mobility 
markets. Welles \& Nieuwenhuis (2012) have documented various indices of resistance to change within the automobile sector as a typical example of this sort of stress.

In sum, we observe a permanent flux new actors coming in to the growing eco-mobility sector (some from elsewhere in the automobile sector, others from outside); we observe various new forms of matching up of features of the new technologies with patterns of consumer use; and we observe radical changes in the composition of the associated value chains - or, in other terms, of the "life cycle" of eco-mobility from the cradle (raw materials, energy sources, the technologies themselves) to the "end-user" and beyond (network renewal, recycling and re-use of worn components, controlled solid waste disposal...). This restructuring all along the value chains corresponds, in the evolutionary vision of "creative destruction", to the emergence of a radically new opportunity set for shared value creation (Porter \& Kramer 2011).

\subsection{Industrial reorganisation and modification in the value chain}

One feature of eco-mobility innovation is that established actors within the automobile sector find themselves collaborating with a multitude of new entrants bringing the necessary complements of technology and know-how. A necessary first step in this process, is that of the partners' "getting to know each other". This is a mutual discovery and learning process (Faucheux \& Nicolaï 1998) that can take substantial time and resources given the diversity of the new partners' experience (production process, workforce organisation, regulatory environment, markets and relations with clients), often taking place in cross-country, multilingual and multinational environments.

The partnership structures that formalise the new business relations, are de facto innovations in cooperative economic governance (Ring \& van de Ven 1994). There is a sort of voluntary association, expressing a relationship of interdependence between two (or more) actors in the value chain, situated at different points or levels within the sector. Such partnerships in operational terms will display three features of tacit or formal contracts:

- A behavioural component: the actors should be united in a "win-win" logic, with an attitude of shared or reciprocal confidence in .

- An knowledge management component: The partners will put in place procedures for information sharing, so as to reduce information asymmetries and to harmonise management tools and reporting procedures between partners (thus building confidence as well as increasing efficiency). 
- An organisational component: The partners will seek to establish frameworks such as joint projects or task forces requiring collaboration between partners, in this way both promoting mutual understanding and encouraging "fair play (that is, introducing social control mechanisms reducing dangers of free-rider or opportunistic behaviour and, providing incentives for success in joint ventures).

Clearly, the implementation and maintenance of such structures can be costly and complicated, because it has to be achieved for each partnership axis at each level of the sector. In the case of eco-mobility, there are working relations to be established in some cases between partners that have, in the past, habitually been linked hierarchically (e.g., a car constructor and a supplier of components) and, in other cases between new partners who historically have no evident hierarchy (e.g., a car constructor and a company manufacturing batteries).

For more than half a century (notably during the decades after the $2^{\text {nd }}$ World War) the value chain of the automobile sector has had a fairly homogeneous form: research and design; primary materials; tools; component parts; assembly; marketing; distribution; financing; after-sales service. Today, at every one of these steps or departments, the eco-mobility sector incorporate new partners, meaning the invention of workable business models, information sharing protocols, and so on. In the tabular schema below, taken from Midler et alii (2012), we give an impression of some of the key nodes or steps in the emerging value chain for electric vehicles.

At each step, the new partners in eco-mobility can themselves vary greatly in character. On the supply side, there are small highly specialised "start-up" companies, notably for electrical mobility and IT, whose role may be indispensable but whose independent market clout is limited. And equally there are very large corporations (such as Bolloré, Google and Mitsubishi) choosing to diversify into eco-mobility on the margins of their established market presence. 


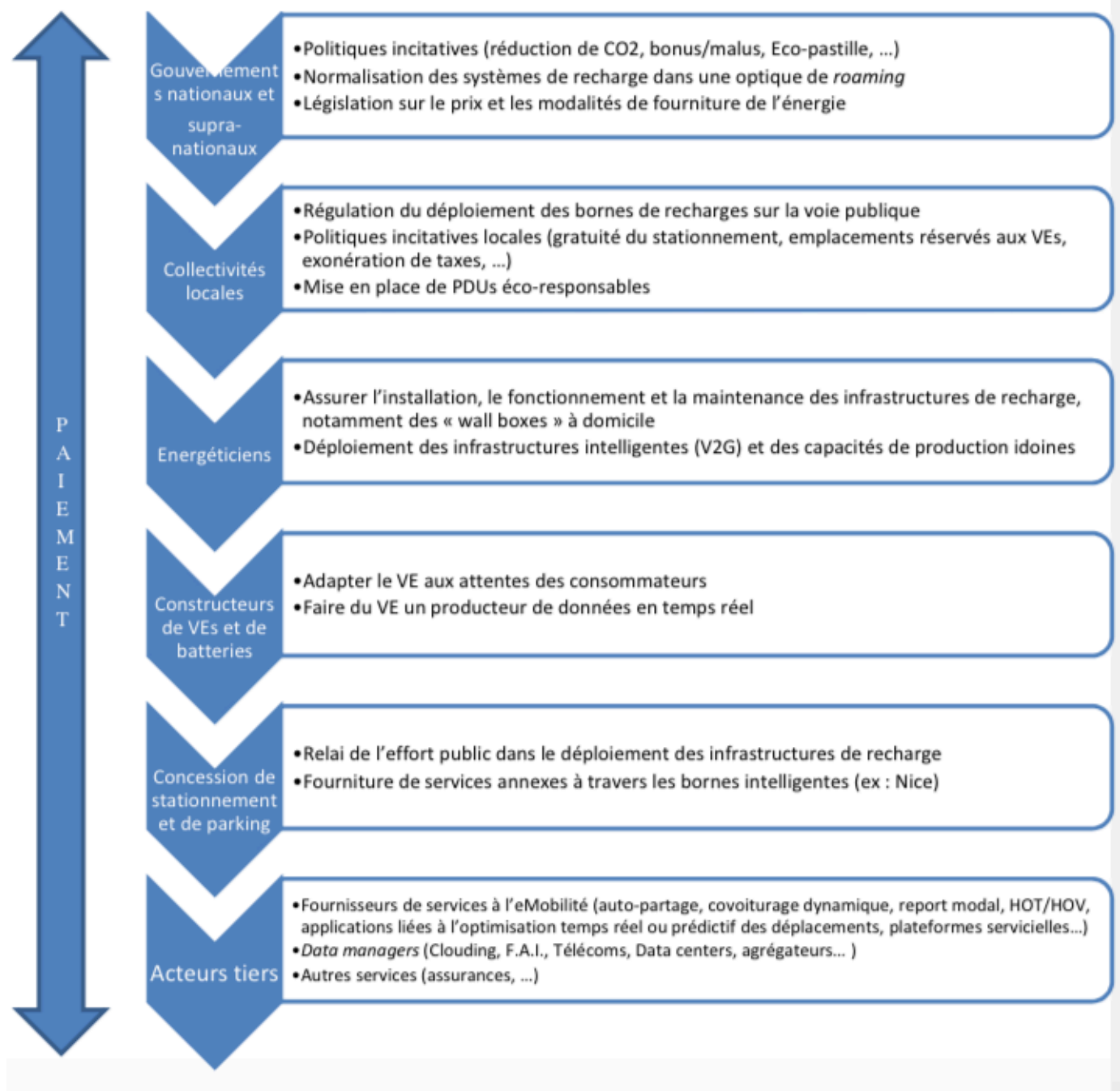

Just as the partner mix is changing, so also is the type of product or service. One of the most striking features is the investment in the vision of the automobile not as a possession but as simply an element in the mobility chain. An illustration is the B2B model, where a mobility operator makes available to users the means of transport adapted to their needs (e.g., a realtime multimodal service; Peugeot's Mu; the Orange fleet of 'connected' vehicles; Citroën with a high degree of personalisation of the vehicle). The car constructor is induced, in new ways, to conceive their products to respond to new individual and collective definitions of mobility "needs".

This combination of new technological possibilities and new conceptions within society of the mobility "need" (or needs), has the effect of completely reshuffling the deck as far as market opportunity is concerned. In this regard, it is useful to make a distinction between opportunities perceived by existing actors as enlargement or extension of their operations, and opportunities for new actors, for proposing radically new or different forms of mobility and of shared value creation. The high barriers to entry characteristic of the transport sector, make it unlikely to see 
new entrants into already established markets. However, the development opportunities available to first comers in the emerging markets are likely to be the object of fierce competition including both large and small new players as well as some of the established sector actors in the battle for market shares and for a 'cut' in the expected new shared value (Aghion \& Griffith 2005). And, as in all cases of disruptive innovation, part of the competition will be to influence the evolution of the "infrastructures" - the regulatory environment, the tax and other fiscal conditions, and the public sector investments in mobility networks and information systems that determine the relative profitability and scope of different service concepts and partnership forms.

\subsection{Confronting the new competitive environments:the example of VeDeCom}

The volatility of the eco-mobility ecosystem, with a high flux of new entrants, experiments in business models and partnerships, and speculation over the future definition of mobility "need", means that all investment is risky. It is impossible to predict with confidence at this stage, what the size of the different markets and the relative mix of different eco-mobility services will be in 5 or 10 years. It is therefore impossible to quantify far in advance the investment requirements at each step along the value chain and the size of the markets.

In this climate of uncertainty, individual firms (large and small) are highly vulnerable. As such, the choices of economic model, of business partnerships and of cooperative governance as described above, are strategies for managing risks. They have a role of building solidarity and resilience, of introducing some forms of contractual stability (thus reducing short-term risks), thus increasing the capacity of individual partners to embark in the exploration of market possibilities. At the same time, businesses must individually and in partnership, monitor market conditions, regularly reassess future prospects, and adapt their investment and marketing plans. This need for flexibility pleads in favour of the Open Innovation or 'Open Business' models (Chesbrough 2003, 2006).

These 'open' organisational models explicitly leave a place for adjustment to changing conditions and for the development of new relations (including new partners). Questions inevitably arise as to relative responsibilities, the dividing line between commercial secret and transparency in open cooperation, the principles for shares of value-added (if and when it occurs) and, the sharing of risks. Following the arguments developed by Palay (1984), Christensen et al. (2006), Caglio \& Ditillo (2008) and others, one of the keys to success in collaborative business ventures is to focus on the challenge of value-creation in the emerging ecosystem, with partnership governance through a variety of operational agreements: 
- Promoting the explicit alignment of the interests of business partners, so as to provide a clear basis for cooperation;

- Ensuring the coordination of joint work programmes with a clear division of labour agreed by all parties, and accountability in terms of results;

- Ensuring that the added-value created in collaboration, is shared in an equitable way and not appropriated by one partner in the commercial relation.

These sorts of collaborative procedures are intended to enhance confidence between partners and, to build a joint capacity to analyse changes in market opportunities and to respond to new opportunities and risks. In the Open Innovation model, the frontiers between business partners and with the rest of the ecosystem are porous, so as to permit interactions and ongoing learning. Rather than operate in a closed universe, each enterprise is open to the exploitation of new knowledge (coming from outside-in), and open to the development (from the inside-out) of new marketing practices and new business relations.

We conclude with an example in France of the self-conscious implementation of the Open Innovation model for eco-mobility. This is the establishment of the Institut VeDeCom as a state sponsored framework for the "clustering" of research and industrial partners in the eco-mobility domain.

- The first stage in this clustering process took place during 2008-2009, with the establishment of a collaborative 'platform' of key actors in the French automobile sector.

- The second phase was the establishment in 2012 of the partnership institute VeDeCom broadening the perimeter to include a full spectrum of eco-mobility innovation actors research and territorialgovernance as well as business partners.

The VEDECOM Institute (the name in French stands for Véhicule Décarboné Communicant et sa Mobilité, which means "The carbon-free, communicating vehicle and its mobility") is one of a small number of national Institutes for Energy Transition set up in France during the past five years as part of the Plan d'Investissement d'Avenir (the French national long-term research and technology investment plan for the future). As a French public-private partnership, the VEDECOM Institute is thus based on a novel and unprecedented collaboration between industries of the automotive sector, infrastructure and services operators in the mobility ecosystem, academic research institutions, and local communities in the Ile de France region. This illustrates plainly the central thesis of this paper, of the extent to which "disruptive" innovation can induce radical changes to the partnership structures and business models of actors around the sectors of production and wider society concerned. 
VEDECOM aims at becoming a European innovation leader in the fields of electrified vehicles, autonomous and connected cars, and new infrastructure and services for shared mobility and energy. In the pursuit of this goal, they have broken down old boundaries and built new relationships at all levels, in order to engage an "open innovation" process in several senses of the term: open to new ideas, open to new business models with consumers, open to new working relationships with territorial authorities, notably for mobility services, networks and infrastructures (cf., Amirall \& Casadesus-Masanell 2010). The VeDeCom partners identify explicitly the challenge of building a common platform as a springboard for launching into an asyet poorly defined future. Among the mechanisms of collaboration, they have defined:

- A domain of pre-competitive innovation and intellectual property (IP) that is created collaboratively and that can thus freely be exploited by partners (including third parties) in the subsequent development of products and services;

- A phase described as pre-normative, meaning activity prior to the establishment of regulations, at local, national and European levels, concerning the new technologies, products and service provision, ensuring that the development of rules (including public and user safety, sharing of responsibility across public and private authorities, regulation of trades and workforce organisation, data security, commercial agreements, etc.) is proactive and collaborative (multi-stakeholder), and not a reactive process after problems emerge. This can be criticised as industry capture of the regulatory processes, and can also be seen as an explicit form of multi-stakeholder governance.

Of course, there are many tensions, risks and potential difficulties remaining to be addressed by the VeDeCom consortium. The rules and boundaries for sharing of IP (foreground, side-ground, background) will undoubtedly require regular attention. There will be rivalries and jockeying for relative power. Nonetheless, the temptations of "free rider" and opportunistic behaviour, can be counter-balanced by incentives to share - in financial, IP and prestige terms - the fruits of collaborative efforts. For example, patents applied for and obtained on behalf of the collective of partners, can be a strong mechanism to enhance capacity and reputation in a non-competitive "win-win" logic within the group (cf., Bureth et alii 2007). The challenge is thus to be a "winner" collectively, not to win against other partners in the team. The open innovation process is thus, very much larger than simple sharing or synergies of technologies and know-how. It extends to the "engineering" and the governance of partner relations at every level, with the accent on ongoing team building in the search of complementarities and new shared opportunities 


\section{§3. Conclusion}

The transition likely to take place from the prevailing automobile value chain to that of new ecomobility solutions, is a complex one - being simultaneously «pulled » by new uses and needs, and « pushed» by radical technological innovation. This gives rise, inevitably, to a process of coconception engaging a diversity of actors and sectors, whose respective strategies and motivations are by no means aligned at the outset.

These actors are all engaged, at different levels in the market, in the experimentation of viable business models, in a context where high infrastructure costs can be dissuasive given the uncertainties that still prevail as to the future « ecosystems » of mobility.

The various business partners are often of extremely different size, coming from manufacturing and service sectors with very different patterns of activity, and with very different forms of coordination (e.g., sectoral federations, professional associations, and so on). What solutions will emerge for working partnership arrangements in this context?

At a cross-cutting level, the penetration rate of e-mobility solutions will depend very much on whether or not there is sustained political will. Marginal tax or other financial advantages (such as an "environmental bonus" for car buyers) are not sufficient on their own to incite electric vehicle purchase nor to provoke adhesion to new practices of eco-mobility and the associated services. Over and above price, consumer willingness to adopt new practices is impaired by uncertainties about, for example, the scope and ease of electric vehicle use in different situations and, the uneven visibility of services. The absence or poor visibility of recharge points is a major psychological barrier for many people, especially in a context where the limited autonomy of electric car batteries is often highlighted as a weak point in the acceptability/attractiveness of electric vehicles.

Infrastructure development in support of individual e-mobility, is thus seen as a necessary condition for the substantial uptake of eco-mobility innovations. This is an illustration of a "catch-22" phenomenon often observed in the literature about incentives - that (apart from a small percentage of pioneers), consumers will generally wait until a visible support and service network is established before making the jump to electric vehicle purchase or use; and private sector service providers will often wait until the market is clearly developed before engaging significant investments. This sort of situation (described theoretically as non-cooperative games and the "Prisoners' Dilemma") lead to dead-ends that can be opened out only through intervention at a higher level, such as public policy (with its attendant controversies and risks of 'picking winners') or, in some cases, a change in technology paradigm that becomes the new norm. 


\section{§4. References}

Aghion P., Griffith R. (2005), Competition and Growth: Reconciling Theory and Evidence, Cambridge, EUA: MIT Press, 120p.

Almirall, E., Casadesus-Masanell R. (2010), "Open vs. Closed Innovation: A Model of Discovery and Divergence", Academy of Management Review, 35(1), January, pp. 27-47.

Amit R., Zott C. (2001), "Value Creation in e-Business", Strategic Management Journal, Special Issue: Strategic Entrepreneurship: Entrepreneurial Strategies for Wealth Creation, 22(6-7), pp. 493-520, June July

Astley W. G., Fombrun C. J., (1983), "Collective strategy: social ecology of organizational environments", Academy of Management Review, 8(4), pp. 576-587

Azzone, G., Noci, G. (1998), "Seeing ecology and "green" innovations as a source of change", Journal of Organizational Change Management, 11(2), pp.94-111.

Barabel M., Combes M., Meier O., Nicolaï I., (2010), "Perception and legitimation of CSR within a multinational firm: the case of the Dexia group", Revue internationale de psychosociologie.

Baromètre AramisAuto - TNS Sofres (2013), « Les Français et l'Automobile », mai, 31p.

Bureth A., Müller M., Pénin J., Wolf S., (2007), "Brevet, innovation modulaire et collaboration : Le cas des vaccins géniques", Revue d'Economie Industrielle, 4(120), pp. 135-154

Caglio A., Ditillo A., (2008) "Review and discussion of management control in inter-firm relationships: Achievements and future directions", Accounting, Organizations and Society, 33(7-8), p. 865-898.

Carrillo-Hermosilla J., Rio del P., Könnölä T., (2010), "Diversity of eco-innovations: Reflections from selected case studies", Journal of Cleaner Production, 18, pp. 1073-1083

Chesbrough H. (2003), Open Innovation - The New Imperative for Creating and Profiting from Technology, Harvard Business School Press.

Chesbrough H. (2006), Open Business Models, Harvard Business School Press.

Christensen C. (2006), "The Ongoing Process of Building a Theory of Disruption", Journal of Product Innovation Management, 23(1), 39-55.

Christensen, C.M., Johnson M.W., Rigby D.K, (2002) "Foundations for Growth: How to Identify and Build Disruptive New Businesses", Sloan Management Review, Spring, 43(3), pp. 22-32.

Dal Bo E., (2006), "Regulatory Capture: a review“, Oxford Review of Economic Policy, 22(2), pp. 203-25

Dantan S. Bulteau J., Nicolaï I. (2015), "How to enhance the use of multimodal information? Evidence from the Plateau-de-Saclay", International Conference of Public Policy (ICPP), Milan 2015.

Davis F.D. (1989), "Perceived usefulness, perceived ease of use, and user acceptance of information technology“, MIS Quarterly, 13, pp.319-339.

Demil B., Lecocq X. (2010), "Business model evolution: in search of dynamic consistency", Long Range Planning, 43(2), pp. 227-246

DiMaggio, P., Powell W., (1983), "The Iron Cage Rivisited: Institutional Isomorphism and Collective Rationality in Organizational Fields", American Sociological Review, 48, pp. 147-60

Donada C., (2014), "Pour une réingénierie des partenariats verticaux : le cas de la plateforme de la filière automobile“" Essec Working paper, n 1401

European Commission, (2011), White paper, Roadmap to a Single European Transport Area - Towards a competitive and resource efficient transport system 
Fan X., Bourg D., Erkman S., (2006), “L'economie circulaire en Chine. Vers une prise en compte de l'environnement dans le systeme economique chinois?", Futuribles, 324, novembre.

Faucheux S., Nicolaï I. (1998), “Les firmes face au développement soutenable : changement technologique et gouvernance au sein de la dynamique industrielle“, Revue d'Economie Industrielle, 83(1), pp.127-146.

Faucheux S., Nicolaï I. (2011), "IT for Green and Green IT: A Proposed Typology of Eco-Innovation", Ecological Economics, nº70, pp.2020-2027.

Freeman C., Soete L., (1987), Technical Change and Full Employment, Blackwell, Oxford and New York

Frosch, R.A., (1995), "Industrial Ecology, Adapting Technology for a Sustainable World“, Environment, December, pp.16-24

Ganguly A., Nilchiani R., Farr J. (2010), “Defining a Set of Metrics to Evaluate the Potential Disruptiveness of a Technology“, Engineering Management Journal, 22(1), pp. 34-44.

Greenwood, R., Suddaby, R., Hinings, C.R. (2002) "Theorizing change: the role of professional associations in the transformation of institutionalized fields", Academy of Management Journal, 45, pp.58-80.

Hellström Th. (2007), "Dimensions of environmentally sustainable innovation: the structure of ecoinnovation concepts“, Sustainable Development, 15(3), pp.148-159, May/June

Klemmer P., Lehr U., Lobbe K., 1999, "Environmental Innovation: Incentives and Barriers", Analytica, Berlin

Mackay M., Metcalfe M. (2002), "Multiple Methods Forecasts for Discontinuous Innovations", Technological Forecasting and Social Change, 69, pp.221-232.

Mau P., Eyzaguirre J., Jaccarda M., Collins-Dodd C., Tiedemann K. (2008), “The 'Neighbor Effect': Simulating Dynamics in Consumer Preferences for New Vehicle Technologies“, Ecological economics, 68, pp.504-516

Midler C., R. Maniak, Beaume R. (2012), Réenchanter l'industrie par l'innovation : l'expérience des constructeurs automobiles, Paris, Fra : Dunod, 208p.

Moingeon B., Lehmann-Ortega L. (2006), “Genèse et Déploiement d’un Nouveau Business Model : l’Etude d’un Cas Désarmant“, M@n@gement, 13(4), pp.266 - 297

Nelson R., Winter S. (1982), An Evolutionary Theory of Economic Change, Cambridge, EUA: Harvard University Press, 454p.

Nill J., Kemp R. (2009), "Evolutionary Approaches for Sustainable Innovation Policies: From Niche to Paradigm? “ Research Policy, 38, pp. 668-680

Nonaka I., Takeuchi H., (1997), La connaissance créatrice, De Boeck université, Paris/Bruxelles.

Norgaard, R.B. (1994). Development Betrayed: The end of progress and a coevolutionary revisioning of the future, London, Routledge.

OECD, (2008, "Towards green IT strategies ; Assessing Policies and Programmes on IT and the Environment", Working Party on the Information Economy, DSTI/ICCP/IE(2008)3/FINAL.

Orsato R.J. (2006), “Competitive Environmental Strategies: When Does It Pay to be Green ?", California Management Review, 48(2), Winter

Osterwalder A., Pigneur Y. (2011), Business Model Generation, Pearson, 288p.

Palay T., (1984), “Comparative institutional economics: The governance of rail freight contracting“, Journal of Legal Studies, 13, June, pp. 265-288.

Passet, René (2010), Les Grandes Représentations du Monde et de l'Economie à travers l'histoire: De l’Univers magique au Tourbillon Créateur, LLL Les Liens qui Libèrent, Paris, 950pp.

Pillot J. (2011), "Vers une mobilité décarbonée : quels écosystèmes d'affaire, quels positionnements stratégiques?", rapport VeDeCoM

Porter M.E., Kramer M.R. (2011), “Creating Shared Value“, Harvard Business Review, January

Pujari D., 2006, "Eco-innovation and new product development: understanding the influences on market performance", Technovation, 26(1), p. 76-85 
Rennings K., 2000, "Redefining innovation - eco-innovation research and the contribution from ecological economics", Ecological Economics, 32, pp.319-32

Ring P.S., Van de Ven A.H., "Development processs of cooperative interorganizational relationships", Academy of Management Review, 19(1), pp. 90-118.

Schumpeter J., 1934, The theory of economic development, Harvard U. Press, Cambridge.

Teece D.J. (2007), "Explicating dynamic capabilities: the nature and microfoundations of (sustainable) enterprise performance“, Strategic Management Journal, 28(13), pp. 1319-1350, December

Van der Vooren A., Alkemade F. (2012), "Managing the Diffusion of Low Emission Vehicles", IEEE Transactions on Engineering Management, 59(4), 728-740.

Weick, K.E., Roberts, K.H. (1993). "Collective mind in organizations: Heedful interrelating on flight decks", Administrative Science Quarterly, 38, 357-381.

Wells P, Nieuwenhuis P. (2012), "Transition Failure: Understanding Continuity in the Automotive Industry“, Technological Forecasting and Social Change, 79(9), 1681-1692. 